\title{
Editorial: On IRIE Vol. 19
}

What is the reputation of IRIE? How can it be measured? There are, of course, the classical techniques to assess the reputation of a scientific journal: mainly by indices it is listed in, citation indices, the TSI, but also the price tag of an issue and of course the reputation of its authors, editors, etc. They are all widely used in this regard but still, they all stem from the Gutenberg Galaxy, so the question remains: Are they still valid in the cyberworld, valid for a scientific online journal focused on a very special, very innovative area of expertise?

Could the indications of reputation in the cyberworld (in fact, they also enjoy a rather classical status by now) be of any help:

- Ranking in google? In fact, we are \# 2 for the keyword "information ethics" - out of 192,000,000 after all (as of $23^{\text {rd }}$ July 2013) - but still second to Wikipedia. Does this mean the entry on "information ethics" in Wikipedia deserves a higher scientific reputation than IRIE?

- Number of visitors to the web-site? We can proudly state that the counter shows more than 83,000 visits (also as of $23^{\text {rd }}$ July 2013) and still counting. That's a rather large number for a scholarly journal. Still, there are some web-sites with far more visitors that without any doubt would be assigned a much lower scholarly reputation than IRIE!

- Number of back-links, comments, tweets, etc.? Do they or a mixture of all of them (by the way the latter would finally lead to the ranking in google again if all these ingredients are put together into a proper formula) correctly reflect the scholarly quality of IRIE in the cyberworld?

Indeed, the question about how to assess the scholarly reputation of an online journal such as IRIE is not yet answered. And precisely that is reason enough for us to raise this very question in an issue of IRIE - of course on a more conceptual level, not necessarily narrowed to the assessment of the reputation of IRIE itself.

Thanks to Michael Eldred's solid work, we received some very illuminating and inspiring contributions on this subject. And yet, only one thing is certain: To the degree this issue contributes to raising if not solving the question of reputation in the cyberworld, it contributes also to the reputation of IRIE in the cyberworld - as well as in the world in general and the scholarly world in particular. So please, see for yourself! There's good reason that in philosophical discourse this latter is the only thing that counts.

Sincerely yours,

the editors. 